\section{Stability of the arterial to end-tidal carbon dioxide difference during anaesthesia for prolonged neuro- surgical procedures}

Sharad K. Sharma MB BS FFARCSI, Glenn P. McGuire MD, Charles J.E. Cruise MD FRCPC
This study was undertaken to examine the variation of the arterial to end-tidal $\mathrm{PCO}_{2}(\mathrm{~Pa}-\mathrm{PETCO})$ difference during prolonged neurosurgical anaesthesia. Hyperventilation is often used to reduce intracranial pressure in neurasurgical patients. Continuous end-tidal $\mathrm{CO}_{2}$ monitoring is used as a guide between arterial $\mathrm{CO}_{2}$ measurements. We examined the stability of the $\mathrm{Pa}-\mathrm{PETCO} \mathrm{C}_{2}$ difference in 21 patients undergoing elective craniotomies lasting greater than four hours. $A$ balanced neuroanaesthetic technique was used with the ventilation variables at the discretion of the attending anaesthetist. Once patients were positioned for surgery, simultaneous samples of arterial $\mathrm{PCO}_{2}$ through an arterial catheter, and end-tidal $\mathrm{PCO}_{2}$ via a mass spectrometer were obtained. The $\mathrm{Pa}-\mathrm{PETCO}$ differences of each patient were plotted against time and a slope was derived with simple linear regression. The mean slope for all patients was then computed. There were no changes in the $\mathrm{Pa}-\mathrm{PETCO}_{2}$ difference with time $(P>0.05)$ suggesting a constant relationship between the arterial and end-tidal $\mathrm{PCO}_{2}$ measurements over time. We conclude that end-tidal $\mathrm{PCO}_{2}$ can be used as a reliable

\section{Key words}

ANAESTHESIA: neurosurgery;

CARBON DIOXIDE: monitoring, tension, arterial, gradients, end-tidal;

MEASUREMENT: capnometry.

From the Department of Anaesthesia, Toronto Western

Division, The Toronto Hospital, University of Toronto,

Ontario, Canada.

Data presented in part at the Canadian Anaesthetists'

Society Annual Meeting in Halifax, Nova Scotia, June 1993. Address correspondence to: Dr. Charles J.E. Cruise,

Department of Anaesthesia (Toronto Western Division), The

Toronto Hospital, 399 Bathurst Street, Toronto, Ontario,

Canada MST 2S8.

Accepted for publication January 30, 1995. guide to estimate arterial $\mathrm{PCO}_{2}$ during neurosurgical procedures of greater than four hours duration once the $\mathrm{Pa}-\mathrm{PETCO}_{2}$ difference has been established.

Cette étude vise à étudier les variations de la différence entre la $\mathrm{PaCO}_{2}$ artérielle et télé-expiratoire $\left(\mathrm{Pa}-\mathrm{PETCO} \mathrm{CO}_{2}\right)$ pendant l'anesthésie neurochirurgicale de longue durée. On utilise souvent lhyperventilation pour diminuer la pression intracranienne en neurochirurgie. Le monitorage continu de $\mathrm{CO}_{2}$ téléexpiratoire est utilisé entre les analyses du $\mathrm{CO}_{2}$ artériel. Nous étudions la stabilité de la différence $\mathrm{Pa}-\mathrm{PETCO} \mathrm{O}_{2}$ chez 21 patients soumis à une craniotomie réglée dont la durée dépasse quatre heures. Une technique neuro-anesthésique équilibrée est utilisée dont les paramètres respiratoires sont laissés à la discrétion de l'anesthésiste responsable. Une fois les patients installés pour la chirurgie, des échantillons de sang pour la $\mathrm{PaCO}_{2}$ sont prélevés par un cathéter artériel, et ceux la $\mathrm{PCO}_{2}$ télé-expiratoire par un spectromètre de masse. Pour chaque patient, un tracé des différences $\mathrm{Pa}-\mathrm{PETCO}_{2}$ mis en rapport avec le temps est réalisé et une courbe avec régression linéaire simple en est dérivée. La pente moyenne pour tous les patients est ensuite calculée. Le fait quil n'y ait pas de changement de la différence $\mathrm{PaCO}_{2}-\mathrm{PETCO}_{2}$ en rapport avec le temps $(P>0,05)$ suggère que la relation entre les mesures artérielles et télé-expiratoires de la $\mathrm{PCO}_{2}$ est constante dans le temps. Nous concluons que la $\mathrm{PCO}_{2}$ télé-expiratoire estime de façon fiable la $\mathrm{PCO}_{2}$ artérielle pendant les interventions neurochirurgicales qui durent quatre heures et plus, une fois la différence $\mathrm{Pa}-\mathrm{PETCO}_{2}$ établie.

One of the major treatment modalities used by anaesthetists for the management of raised intracranial pressure (ICP) in neurosurgical patients is hyperventilation, which reduces arterial $\mathrm{PaCO}_{2}$. Hyperventilation to a $\mathrm{PaCO}_{2}$ of $25-30 \mathrm{mmHg}$ is the mainstay of acute and subacute management of raised ICP. It is well known that $\mathrm{PaCO}_{2}$ correlates inversely with cerebral arterial resistance. As a con- 
sequence, hyperventilation can effectively reduce ICP by reducing cerebral blood flow and volume. ${ }^{1}$ Therefore, it is important that the anaesthetist be aware of the $\mathrm{PaCO}_{2}$ values during procedures where raised ICP is a potential problem.

Hyperventilation is only effective when the $\mathrm{PaCO}_{2}$ reactivity of the cerebral vasculature is normal and intact. The $\mathrm{CO}_{2}$ reactivity has also been shown to be present in anaesthetized patients with intracranial space occupying lesions. ${ }^{2}$ Although intermittent arterial blood gas (ABG) samples are routinely analyzed to determine $\mathrm{PaCO}_{2}$ during neurosurgical procedures, anaesthetists also rely on capnometry. End-tidal $\mathrm{CO}_{2}\left(\mathrm{PETCO}_{2}\right)$ values obtained between arterial samples are used as a guide to the efficacy of manoeuvres used to optimize the $\mathrm{PaCO}_{2}$. Hunn and $\mathrm{Hill}^{3}$ have suggested that during anaesthesia in healthy subjects the relationship of arterial to end-tidal $\mathrm{CO}_{2}$ differences $\left.(\mathrm{Pa}-\mathrm{PETCO})_{2}\right)$ is sufficiently constant for end-tidal values to be used for continuous, indirect assessment of arterial $\mathrm{CO}_{2}$.

The validity of using $\mathrm{PETCO}_{2}$ values as a predictor for $\mathrm{PaCO}_{2}$ values has been described in a variety of intraoperative and postoperative settings. ${ }^{4-12}$ To date, we are unaware of any study which addresses the question of validity of $\mathrm{PETCO}_{2}$ values as a reflection of $\mathrm{PaCO}_{2}$ values in neurosurgical procedures. Additionally, neurosurgical procedures tend to be of long duration (often greater than four hours). The objective of this study was to examine the variation of the $\mathrm{Pa}-\mathrm{PETCO}_{2}$ difference during prolonged neurosurgical anaesthesia.

\section{Methods}

Following Institutional Human Ethics Committee approval, informed consent was obtained from 29 patients with ASA physical status I-III undergoing elective craniotomy for removal of cerebral tumour or repair of cerebral aneurysm. To be eligible for the study, anticipated surgical duration had to be greater than four hours.

No sedative premedication was prescribed. In the operating room, routine monitors including electrocardiogram, blood pressure cuff, pulse oximeter, peripheral nerve stimulator and temperature probe were applied. A radial arterial line was inserted under local anaesthesia and a sample obtained for preinduction arterial blood gas analysis. Anaesthesia was induced and the trachea was intubated after fentanyl 3 to $5 \mu \mathrm{g} \cdot \mathrm{kg}^{-1}$, lidocaine 1 to $1.5 \mathrm{mg} \cdot \mathrm{kg}^{-1}$, thiopentone 3 to $5 \mathrm{mg} \cdot \mathrm{kg}^{-1}$, dtubocurarine 3 to $4.5 \mathrm{mg}$, and succinylcholine $1.0-1.5$ $\mathrm{mg} \cdot \mathrm{kg}^{-1}$ or vecuronium $0.1 \mathrm{mg} \cdot \mathrm{kg}^{-1}$. Anaesthesia was maintained using positive-pressure ventilation with nitrous oxide in oxygen (60:40\%), isoflurane 0.5 to $1.0 \%$ (Narcomed 2A North American Drager) and vecuronium for muscle relaxation. The management of ventilatory settings (Drager AV Ventilator) was determined by the attending anaesthetist.

After the patients were positioned and haemodynamically stable, $\mathrm{PaCO}_{2}$ values were sampled via the arterial catheter and $\mathrm{PETCO}_{2}$ values were measured using a mass spectrometer (Model 1700, The Perkin-Elmer Corp.). The mass spectrometer sampling catheter was inserted between the endotracheal tube and the breathing circuit. The PETCO ${ }_{2}$ was taken as the average of three consecutive measurements recorded in rapid succession. $\mathrm{PETCO}_{2}$ is determined as a percentage of dry (water vapour-free) gas by the mass spectrometer. Therefore the measured end-tidal $\mathrm{PCO}_{2}$ was corrected using the following calculation. The saturated water vapour pressure $\left(\mathrm{PH}_{2} \mathrm{O}\right)$ (at the patient's body temperature at the time of sampling) was subtracted from the atmospheric pressure $(\mathrm{PB})$ on the day of sampling and then multiplied by the measured $\mathrm{PETCO}_{2}$ percentage.

$$
\mathrm{PeTCO}_{2} \text { corrected }=\left(\mathrm{PB}-\mathrm{PH}_{2} \mathrm{O}\right) \times\left(\mathrm{PeTCO}_{2} / \mathrm{PB}\right)
$$

The first post-induction measurements were taken as baseline values which were then repeated every hour until the conclusion of the surgery. Simultaneous measurements of ventilatory variables (tidal volume, respiratory rate), blood pressure, pulse and temperature were recorded. The body temperature was measured using an oesophageal thermistor probe (Baxter Pharmaseal 700 series). The arterial blood gases were measured at $37^{\circ} \mathrm{C}$ by a Stat Profile 3 Nova Biomedical gas analyzer. The arterial blood gases were also temperature-corrected to the patients' body temperature. The ABG analyzer was calibrated to the daily atmospheric pressure.

For each patient, the arterial to end-tidal $\mathrm{PCO}_{2}$ difference was plotted against time and the slope derived with simple linear regression. The mean slope for all patients was then computed. To determine whether it deviated from a slope of zero (i.e., no change in the difference with time), a one sample two-tailed Student's $t$ test was performed. Statistical significance was accepted at a level of $P<0.05$. The continuous data (blood pressure, temperature) were analyzed using repeated measures ANOVA. Dunett's multiple comparison test was used to compare each group to baseline. All data are reported as mean \pm standard deviation.

\section{Results}

Twenty-nine patients were studied. Eight patients with duration of surgery of less than four hours were excluded from the final analysis. The demographic data of the 21 patients is presented in Table I. There were seven men and 14 women with an average age of $47.6 \mathrm{yr}$ and weight of $70.4 \mathrm{~kg}$. The average body mass index was 25.9 (six patients had values of greater than 28 and would be clas- 
TABLE I Demographic data $(n=21)($ mean \pm SD)

\begin{tabular}{lc}
\hline Age $(\mathrm{yr})$ & $47.6 \pm 12.4$ \\
$\mathrm{Sex}(\mathrm{male} / \mathrm{female})$ & $7 / 14$ \\
Weight $(\mathrm{kg})$ & $70.4 \pm 14.2$ \\
Height $(\mathrm{cm})$ & $166.0 \pm 9.6$ \\
Body mass index & $25.9 \pm 5.3$ \\
Smokers $/$ non-smokers & $9 / 12$ \\
Preop $\mathrm{PaO}_{2}(\mathrm{mmHg})$ & $90.3 \pm 13.5$ \\
Preop $\mathrm{PaCO}_{2}(\mathrm{mmHg})$ & $37.6 \pm 4.0$. \\
\hline
\end{tabular}

sified as obese). There were nine smokers and twelve non-smokers. With the exception of two patients who had hypertension and two patients who had NYHA class two dyspnoea, no patient had symptomatic clinical evidence of cardiorespiratory disease. The pre-induction blood gas measurements were within the normal range with average $\mathrm{PaO}_{2} 90.3 \mathrm{mmHg}$ (range 71-111 $\mathrm{mmHg}$ ) and $\mathrm{PaCO}_{2}$ $37.6 \mathrm{mmHg}$ (range $30-42 \mathrm{mmHg}$ ) suggesting no severe pulmonary disease in the study group.

Craniotomies were performed for thirteen brain tumours, six cerebral aneurysms and two acoustic neuromas (Table II). Fifteen patients were positioned supine with the head turned to one side. Three patients each were in the prone and lateral positions (Table III). All patients had $15^{\circ}$ head-up tilt. The ventilatory settings were adjusted to maintain mild hyperventilation using tidal volumes of $10-14 \mathrm{ml} \cdot \mathrm{kg}^{-1}$ and respiratory rates of 10-14 breaths $\cdot \mathrm{min}^{-1}$. The $\mathrm{PaCO}_{2}, \mathrm{PETCO}_{2}$, haemodynamic and temperature data over time are summarized in Table IV.

The mean Pa-PeTCO ${ }_{2}$ differences of the 21 patients are plotted over time in Figures 1 and 2. The mean value of the initial baseline $\mathrm{Pa}-\mathrm{PETCO}_{2}$ difference was 4.6 $\mathrm{mmHg}$ (range 0.8-9.3). There were no changes in the $\mathrm{Pa}-\mathrm{PETCO}_{2}$ differences with time $(P>0.05)$ suggesting a stable relationship between the arterial and end-tidal $\mathrm{PCO}_{2}$ measurements over time (Figure 1). No patient at any time had a negative $\mathrm{Pa}-\mathrm{PETCO}_{2}$ difference. The $\mathrm{Pa}-\mathrm{PETCO}{ }_{2}$ differences corrected to the patient's temperature were smaller $(2.8 \mathrm{mmHg}$ at time zero) and did not change with time $(P>0.05)$ (Figure 2).

There was no change in mean arterial blood pressure over time $(P>0.05)$. Due to exposure while positioning and draping, body temperature was low initially but increased steadily once warming measures were instituted (Figure 3). Body temperatures at three and four hours were elevated when compared with baseline values $(P$ $<0.01$ ).

\section{Discussion}

The mean value of the $\mathrm{Pa}-\mathrm{PETCO}_{2}$ difference found in our study $(4.6 \pm 2.5 \mathrm{mmHg})$ is similar to clinical values
TABLE II Procedures

\begin{tabular}{lr}
\hline Brain tumour & 13 \\
Cerebral aneurysm & 6 \\
Acoustic neuroma & 2 \\
\hline & \\
& \\
TABLE III Position & \\
\hline Supine & 15 \\
Lateral & 3 \\
Prone & 3 \\
\hline
\end{tabular}

previously reported. Collier et al. ${ }^{14}$ determined the arterial to end-tidal $\mathrm{PCO}_{2}$ difference to be $0.9 \pm 1.8$ in healthy awake volunteers. Nunn and Hill ${ }^{1}$ noted a mean value of $4.6 \pm 2.5 \mathrm{mmHg}$ which remained sufficiently constant for $\mathrm{PETCO}_{2}$ to be useful in predicting $\mathrm{PaCO}_{2}$ during anaesthesia with either controlled or spontaneous respiration. Takki et al. ${ }^{15}$ also reported a similar difference of $3.5 \pm 2.0 \mathrm{mmHg}$ in 24 stable patients with an excellent correlation between mean values of $\mathrm{PaCO}_{2}$ and $\mathrm{PETCO}_{2}$ in groups of patients with or without lung disease during controlled ventilation using different respiratory rates and tidal volumes.

There are several factors which influence the $\mathrm{Pa}-\mathrm{PETCO}{ }_{2}$ difference. Askrog et al. ${ }^{16}$ saw a progressive increase in the difference over time in seven patients undergoing major general surgery when deliberate hypotension was induced, due to an increase in dead space. In our study there were no major haemodynamic changes. Position changes, such as head up tilt ${ }^{17}$ or the kidney rest position ${ }^{18}$ have been shown to influence the $\mathrm{Pa}-\mathrm{PETCO} \mathrm{O}_{2}$ difference. There were no positional changes in our study, as testing the Pa-PETCO ${ }_{2}$ difference occurred only after the patient had been satisfactorily positioned for surgery.

Arterial to end-tidal $\mathrm{CO}_{2}$ differences have been described in a variety of intraoperative settings including anaesthesia for tubal ligation, ${ }^{4}$ surgery performed during early pregnancy, ${ }^{5}$ Caesarean section, ${ }^{6}$ vascular surgery, ${ }^{7}$ coronary artery bypass grafting in adults ${ }^{8}$ and during repair of congenital cardiac defects in children. ${ }^{9}$ Its potential utility has also been described during weaning of patients from mechanical ventilation after cardiac surgery ${ }^{10,11}$ and during changes in mechanical ventilation in patients on prolonged ventilatory support. ${ }^{12}$ Several investigators ${ }^{7,16,18}$ who have studied the reliability of the end-tidal $\mathrm{CO}_{2}$ as an estimate of arterial $\mathrm{CO}_{2}$ tension in healthy, haemodynamically stable patients have not found it to be consistently reliable. These studies were performed in patients with either abnormal lung mechanics 
TABLE IV $\mathrm{PCO}_{2}$ and haemodynamic variables (mean $\pm \mathrm{SD}$ )

\begin{tabular}{lllllll}
\hline $\begin{array}{l}\text { Time } \\
(\mathrm{hr})\end{array}$ & $\begin{array}{l}\mathrm{PaCO} \\
(\mathrm{mmHg})\end{array}$ & $\begin{array}{l}\mathrm{PETCO} \\
(\mathrm{mmHg})\end{array}$ & $\begin{array}{l}\mathrm{P}(\mathrm{a}-\mathrm{ET}) \mathrm{CO}_{2} \\
(\mathrm{mmHg})\end{array}$ & $\begin{array}{l}\mathrm{HR} \\
\left.\text { (beats } \cdot \mathrm{min}^{-1}\right)\end{array}$ & $\begin{array}{l}\text { MAP } \\
(\mathrm{mmHg})\end{array}$ & $\begin{array}{l}\text { Temp } \\
(\mathrm{m})\end{array}$ \\
\hline 0 & $32.4 \pm 3.9$ & $27.8 \pm 2.8$ & $4.6 \pm 2.5$ & $70.0 \pm 16.1$ & $84.6 \pm 10.4$ & $35.6 \pm 0.9$ \\
1 & $33.2 \pm 4.1$ & $27.6 \pm 3.4$ & $4.6 \pm 2.2$ & $70.2 \pm 16.6$ & $82.7 \pm 10.6$ & $35.4 \pm 0.7$ \\
2 & $32.3 \pm 3.6$ & $27.5 \pm 3.8$ & $4.9 \pm 2.0$ & $72.2 \pm 17.3$ & $83.0 \pm 13.3$ & $35.7 \pm 0.7$ \\
3 & $32.2 \pm 3.0$ & $27.3 \pm 3.0$ & $4.8 \pm 1.8$ & $77.8 \pm 15.0$ & $82.5 \pm 10.5$ & $35.9 \pm 0.8$ \\
4 & $31.3 \pm 3.0$ & $26.9 \pm 2.3$ & $4.4 \pm 2.0$ & $79.2 \pm 17.2$ & $79.6 \pm 10.9$ & $36.0 \pm 0.8$ \\
\hline
\end{tabular}

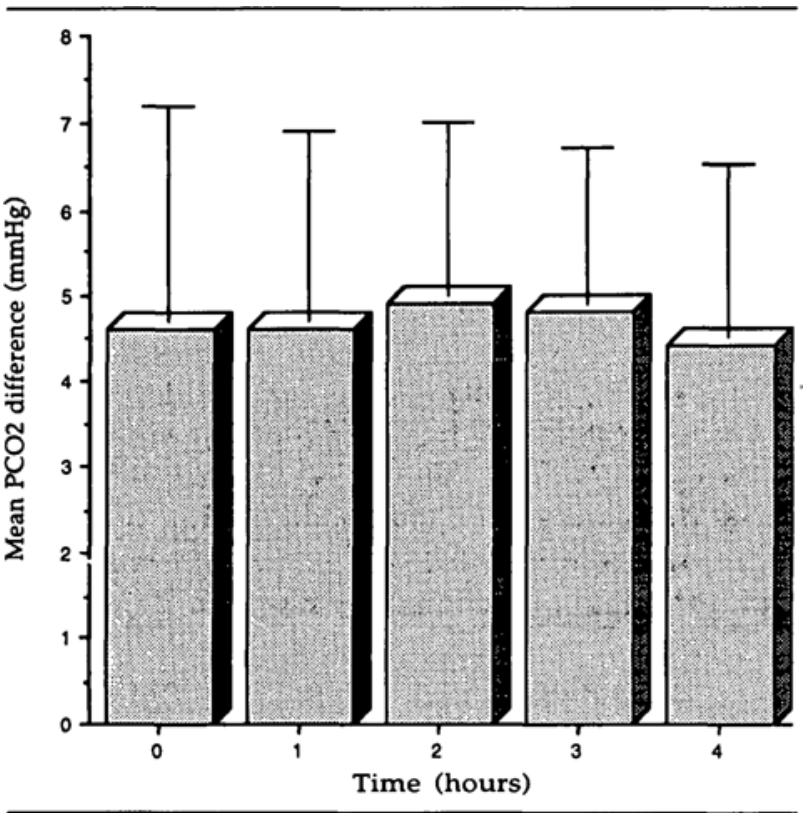

FIGURE 1 The arterial to end-tidal $\mathrm{CO}_{2}$ difference over time for all patients. Data are mean \pm standard deviation.

(e.g., pregnancy, critically ill patients) or during surgical interventions which would cause changes in pulmonary dead space (e.g., major chest or abdominal surgery). In our study, the patients had normal lungs, no surgical insult to the thoracic or abdominal cavity, and were haemodynamically stable. In none of the above studies was a systematic examination of the difference over a prolonged time period undertaken in the intraoperative setting.

Most commonly, the $\mathrm{Pa}-\mathrm{PETCO}_{2}$ difference is positive. A negative value for $\mathrm{Pa}-\mathrm{PETCO}_{2}$ (i.e., $\mathrm{PETCO}_{2}$ greater than $\mathrm{PaCO}_{2}$ ) can occur in patients during general anaesthesia. 'This can occur as a normal physiological variant, ${ }^{1}$ with exercise ${ }^{19}$ or during pregnancy. ${ }^{3-5}$ Tidal volume-dependent negative gradients were observed during exercise. ${ }^{19}$ Fletcher and Jonson ${ }^{20}$ reported negative gradients in $12 \%$ of patients with large tidal volumes and low respiratory rates. An increase in tidal volume and decrease in respiratory frequency causes improved ven-

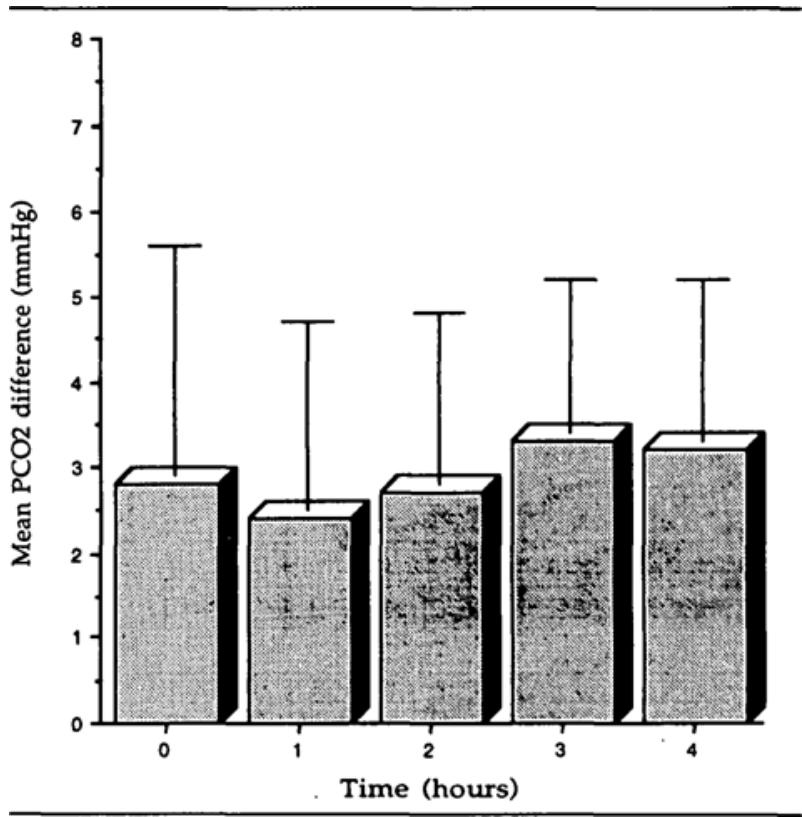

FIGURE 2 The arterial to end-tidal $\mathrm{CO}_{2}$ difference over time using temperature corrected values for $\mathrm{PaCO}_{2}$. Data are mean \pm standard deviation.

tilation of dependent and well perfused alveoli. It also allows the gas from "slow emptying alveoli" (i.e., alveoli with long time constants) to escape due to longer expiratory times. Ordinarily, this gas would have remained trapped in the lungs of patients subjected to small tidal volumes and higher respiratory rates. Therefore, more gas from the areas of lung with higher alveolar $\mathrm{CO}_{2}$ can reach the airway from these "slow emptying alveoli," resulting in a positive slope of the phase III alveolar plateau of expired $\mathrm{CO}_{2}$ on the capnograph. The peak expired $\mathrm{CO}_{2}$ concentration in this instance will equal or exceed the mean arterial concentration of $\mathrm{CO}_{2}$. The $\mathrm{Pa}-\mathrm{PETCO}_{2}$ difference depends both on alveolar dead space and the slope of phase III expired $\mathrm{CO}_{2}$. It has a positive relationship with dead space and negative relation with slope of phase III.

Russell ${ }^{9}$ reported negative differences in $8 \%$ of patients after coronary artery bypass surgery, while Shankar $e t$ $a l$. reported $37 \%$ in early pregnancy ${ }^{4}$ and $50 \%$ in preg- 


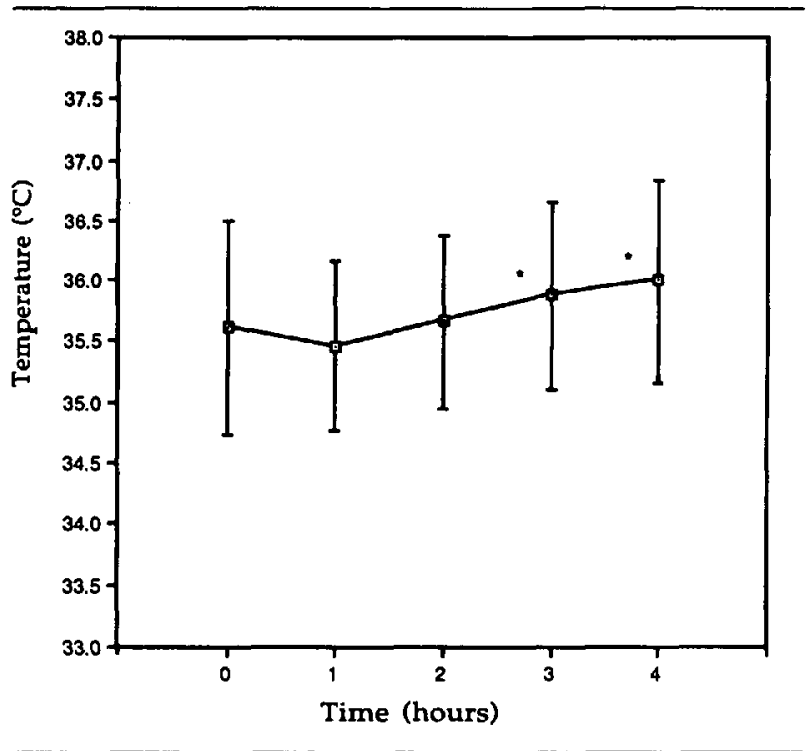

FIGURE 3 Oesophageal temperature $\left({ }^{\circ} \mathrm{C}\right)$ over time. Data are mean \pm standard deviation. Values marked with an asterisk $\left({ }^{*}\right)$ were different from time $0(P<0.01)$.

nant patients during Caesarean section. ${ }^{5}$ We found no negative differences in any of our patients.

The important effect of temperature differences between the patient's body temperature and the blood gas analyzer $\left(37^{\circ} \mathrm{C}\right)$ has been discussed in detail by Severinghaus et al. ${ }^{21}$ Due to changes in $\mathrm{CO}_{2}$ solubility, $\mathrm{pH}$ and $\mathrm{pK}$ of carbonic acid, there is a substantial change in partial pressure with temperature for a given $\mathrm{CO}_{2}$ content of blood. This change results in a decrease in $\mathrm{PaCO}_{2}$ of approximately $2 \mathrm{mmHg} \cdot{ }^{\circ} \mathrm{C}^{-1}$ decrease in temperature. When the results of the $\mathrm{ABGs}$ were corrected to the patient temperature, the differences were smaller $(2.8$ $\mathrm{mmHg}$ at time zero). Despite the smaller difference with temperature correction compared with non-temperature correction $(4.6 \mathrm{mmHg}$ ), neurosurgical patients seldom become so hypothermic $\left(<35^{\circ} \mathrm{C}\right)$ as to make this difference clinically important. We feel the non-temperature corrected $\mathrm{ABGs}$ should be followed, as is our current practice.

As no patient in this study had major haemodynamic changes or severe lung disease, caution must be exercised when generalizing these results. In patients where there are major haemodynamic changes, or the end-tidal value for $\mathrm{CO}_{2}$ does not fit with the clinical picture, it is prudent to verify the situation with $\mathrm{ABG}$ analysis. We conclude end-tidal $\mathrm{PCO}_{2}$ can be used as a reliable guide to estimate arterial $\mathrm{PCO}_{2}$ during neurosurgical procedures of greater than four hours duration. Although Pa-PeTCO ${ }_{2}$ differences varied between patients, once the differences were established, they remained stable over time for a given patient.

\section{References}

1 Hoffman WE, Grundy BL. Neuroanatomy and neurophysiology. In: Barash PG, Cullen BF, Stoelting RK (Eds.). Clinical Anesthesia. Philadelphia: J.B. Lippincott Company, 1989; 819-47.

2 Madsen JB, Cold GE, Hansen ES, Bardrum B. Cerebral blood flow, cerebral metabolic rate of oxygen and relative $\mathrm{CO}_{2}$-reactivity during craniotomy for supratentorial cerebral tumours in halothane anaesthesia. Acta Anaesthesiol Scand 1987; 31: 454-7.

3 Nunn JF, Hill DW. Respiratory dead space and arterial to end-tidal $\mathrm{CO}_{2}$ tension difference in anesthetized man. $\mathrm{J}$ Appl Physiol 1960; 15: 383-9.

4 Shankar KB, Moseley H, Kumar Y, Vemula V, Krishnan $A$. Arterial to end-tidal carbon dioxide difference during anaesthesia for tubal ligation. Anaesthesia 1987; 42: 482-6.

5 Shankar KB, Moseley H, Vemula V, Ramasamy M, Kumar $Y$. Arterial to end-tidal carbon dioxide tension difference during anaesthesia in early pregnancy. Can J Anaesth 1989; 36: 124-7.

6 Shankar KB, Moseley H, Kumar Y, Vemula V. Arterial to end tidal carbon dioxide tension difference during Caesarean section anaesthesia. Anaesthesia 1986; 41: 698-702.

7 Raemer DB, Francis D, Philip JH, Gabel RA. Variation in $\mathrm{PCO}_{2}$ between arterial blood and peak expired gas during anesthesia. Anesth Analg 1983; 62: 1065-9.

8 Fletcher $R$, Veintemilla $F$. Changes in the arterial to endtidal $\mathrm{PCO}_{2}$ differences during coronary artery bypass grafting. Acta Anaesthesiol Scand 1989; 33: 656-9.

9 Lazzell VA, Burrows FA. Stability of the intraoperative arterial to end-tidal carbon dioxide partial pressure difference in children with congenital heart disease. Can $\mathbf{J}$ Anaesth 1991; 38: 859-65.

10 Russell GB, Graybeal JM. Stability of the arterial to endtidal carbon dioxide gradients during postoperative cardiorespiratory support. Can J Anaesth 1990; 37: 560-6.

11 Withington DE, Ramsay JG, Tazi Saoud A, Bilodeau J. Weaning from ventilation after cardio-pulmonary bypass: evaluation of a non-invasive technique. Can J Anaesth 1991; 38: 15-9.

12 Hoffman RA, Kreiger BP, Kramer MR, et al. End-tidal carbon dioxide in critically ill patients during changes in mechanical ventilation. Am Rev Respir Dis 1989; 140 : 1265-8.

13 Shankar KB, Moseley H, Kumar Y. Negative arterial to end-tidal gradients (Letter). Can J Anaesth 1991; 38: 260-1.

14 Collier CR, Affeldt $J E$, Farr $A F$. Continuous rapid infrared $\mathrm{CO}_{2}$ analysis. Fractional sampling and accuracy in determining alveolar $\mathrm{CO}_{2}$. J Lab Clin Med 1955; 45: 526-39.

15 Takki S, Aromaa U, Kauste A. The validity and usefulness of the end-tidal $\mathrm{PCO}_{2}$ during anaesthesia. Annals of Clinical Research 1972; 4: 278-84. 
16 Askrog VF, Pender JW, Smith TC, Eckenhoff JE.

Changes in respiratory dead space during halothane, cyclopropane, and nitrous oxide anesthesia. Anesthesiology 1964; 25: 342-52.

17 Askrog $\mathrm{V}$. changes in (a-A) $\mathrm{CO}_{2}$ difference and pulmonary artery pressure in anesthetized man. J Appl Physiol 1966; 21: 1299-305.

18 Pansard JL, Cholley B, Devilliers $C$, Clergue F, Viars $P$. Variation in arterial to end-tidal $\mathrm{CO}_{2}$ tension differences during anesthesia in the "kidney rest" lateral decubitus position. Anesth Analg 1992; 75: 506-10.

19 Jones NL, Roberison DG, Kane JW. Difference between end-tidal and arterial $\mathrm{PCO}_{2}$ in exercise. J Appl Physiol 1979; 47: 954-60.

20 Fletcher $R$, Jonson. Dead space and the single breath test for carbon dioxide during anaesthesia and artificial ventilation. Br J Anaesth 1984; 56: 109-19.

21 Severinghaus JW, Stupfel MA, Bradley AF. Alveolar dead space arterial to end-tidal carbon dioxide differences during hypothermia in dog and man. J Appl Physiol 1957; 10: 349-55. 